\section{TRENCH SHIN AN INFECTIOUS FIBROSITIS.}

BX GRAHAM CHAMBERS,

LEEUTENANT'-OOLONEL, CANAUIAN ARMY MEDICAL CORPS.

UNDER the heading of infectious fibrositis I propose to discuss a condition with a fairly definite symptom-complex, of which the outstanding symptoms are pain and tenderness on pressure over the tibiæ and tibiales antici.

During practically the whole of the time the British Army has been in France and Flanders, also in Greece, cases of this description have been continually observed. Owing to the frequency of involvement of the shin bones, and the fact that the disease is very common amongst soldiers in the trenches, it is usually called "trench shin." Cases occur, however, in men who have never been in the trenches, indicating that this term cannot be regarded as universally applicable. I suggest that the term "infectious fibrositis" be used to designate this and kindred affections, believing as we do that these diseases are of infectious origin, and that the bacteria or their toxins, causing the morbid condition, show marked elective action for fibrous tissue. They attack the fibrous structures of periosteum, ligament, muscle, nerves, and other parts which are rendered vulnerable by cold and wet, or by any disturbance which interferes with the blood-supply to the part, such as the wearing of puttees. The evidence in favour of this view will be given later in this paper under the heading of " Etiology."

\section{Symptoms.}

In addition to the outstanding symptoms which have already been mentioned-namely, pain and tenderness in the lower limbs, many others may be present, but most of them are not constant. Fever is practically always present in the early stage of the condition, and is generally rather high when the patient first comes under observation, usually about $102^{\circ} \mathrm{F}$., but sometimes as high as $103^{\circ}$ or more. In the great majority of cases it disappears within a few days, but there may be variations in this respect, as we shall see when we come to report illustrative cases of the disease. In one of the cases recorded in this paper fever of a low grade lasted for 20 days, but such persistence is, judging from our own experience, rather exceptional. The pyrexia is invariably accompanied by a polymorphonuclear leucocytosis. The association of fever and leucocytosis with the general clinical manifestations of the disease has led us to the assumption that it is of infectious origin. An interesting feature of the blood count is the presence of leucocytosis after the fever has disappeared. In one of our own cases a leucocytosis of 15,500 was still present eight weeks after the disappearance of fever. The pulse-rate nearly always remains below 100 , but varies to a certain extent according to the temperature.

Headache is the rule in the early stage of the disease, and is described by some of the patients as being "jumping" or "stabbing" in character and worse at night. The temples and forehead are the most common sites of pain, and the patients frequently state that the headache is intensified by rapid movement of the eyes or pressure on the eyeballs. It is also aggravated by coughing, and is not infrequently accompanied by dizziness. In a few of the cases reported the headache has been universal, and in one described by Hunt and McNee it was so severe that lumbar puncture was performed with the object of excluding meningitis.

As already stated, the commonest sites of pain are the shin bones and tibiales antici muscles. The pain is usually of a dull aching character, increased by movement, and relieved to a certain extent by rest. It is practically always bilateral, but a tew cases have recently been reported in which the left shin only was affected. Pain in the back is also a fairly constant symptom. Indeed, it may be said that pain and tenderness on pressure may be present in any part of the surface of the body. The muscles of the arms and thighs are common locations, and in a considerable number of cases the bony prominences and ligaments about the joints, particularly the knees and ankles, are painful and tender. In a small proportion of cases the pain and tenderness may be localised in nerves. A nerve was involved in five of our cases. Of these, the ulnar was the nerve affected in three cases, the median in one, and the radial in one. The symptoms referred to the nerves are those of a neuritis.
The physical examination of the tibiæ does not elicit anything of much diagnostic value, except extreme tenderness on pressure, which has already been referred to as an outstanding symptom of the disease, and I have never been able to satisfy myself that appreciable periostitic thickening is present, and the few skiagrams of the tibix which I have had made do not indicate that it exists. In some cases slight redness of the skin over the internal surface can be made out.

Etiology.

There has been a good deal of discussion as to the etiology of trench shin and trench foot, but the causation stil remains more or less obscure. Three cansative factorsnamely, constriction, infection, and exposure to wet and cold-appear to exist.

Constriation.-Amongst the various contributory factors constriction appears to be a very important one. A clinical study of the cases indicates that the frequency of localisation in the legs is favoured by the wearing of puttees. The fact that most cases occur among privates and non-commissioned officers who are in the habit of wearing puttees supports this view. The lower third of the tibia is not commonly involved, because of the protection afforded this part of the leg by the boot. Anything which tends to impede circulation of the limb, such as tightly tied boot-laces or puttees, may thus contribute to the setting up of the condition. This is recognised by the German writers, who give the disease the name "gaiter pain." In addition to obstructing venous circulation, tight bandaging of the legs by puttees tends to produce a continuous loss of heat. This is important, because cold seems to be one of the chief causative agents of the disorder.

Infeotion. - The view that the disease is primarily due to an infection is gaining more and more adherents, and is supported by the fact that in the Army it is met with almost exclusively in men who have been in or near the trenches. In my opinion the affection is caused by a micro-organism which has a marked elective action upon fibrous tissue. This theory affords an explanation of the occurrence of myalgia, periostitis or osteo-periostitis, rheumatism, and neuritis as symptoms of the disease. The severe headache which occurs in some cases may be due to a fibrositis localised in the meninges of the brain. Whilst the brain tissue itself is insensitive, the dura mater is richly supplied with nerves and therefore a fibrositis localised in the meninges would give rise to pain in the head. This was first called attention to, we think, by Dr. Harry Campbell. If we accept this theory as to the cause of the headache in the affection under consideration we can readily explain all its characteristics (worse at night, aggravated by coughing, great intensity in some cases, \&c.). I would suggest that the indurative headache of gout is due to a similar morbid condition although Llewellyn Jones, who has given special attention to the study of the latter subject, thinks that it is due to myositic deposits.

Rosenow, who has recently made extensive investigations in regard to the elective affinity of certain micro organisms for certain tissues, finds that they undergo mutation on variation of the culture media after successive inoculations into animals, but the factors which determine this localisation are still obscure. His experiments were done by intravenous injection in dogs and rabbits of streptococci isolated from appendicitis, ulceration of stomach and duodenum, cholecystitis, rheumatic fever, erythema nodosum, herpes zoster, epidemic parotitis, myositis and endocarditis. The results showed an elective affinity of these organisms for tissues similar to those from which they had been isolated, those from appendicitis producing lesions in the appendix in 68 per cent., and those from myositis in 75 per cent. of 40 animals, whilst gastric hæmorrhage resulted in a large proportion of those inoculated with cultures obtained from cases of gastric and duodenal ulcer. The gonococcus exhibits a marked affinity for fibrous tissue, Friedländer's bacillus for joints, the tetanus toxin for motor ganglion cells, the diphtheria bacillus for the faucial tonsils, the meningococcus for the meninges, the pneumococcus for the lung, the typhoid bacillus for the lymphatic tissues, the virus of rabies for the central nervous system, that of anterior poliomyelitis for the anterior horns of the spinal cord, the malaria parasite for the red blood corpuscles, and the trichina spiralis for the muscles. By the inoculation of cultures of streptococci (Streptococcus viridans) obtained from rheumatic lesions, he 
produced typical rheumatic myositis in rabbits. It is interesting to note that in Rosenow's experiments the virulence of some of the organisms was increased by exposure to cold. The fact that the virulence of these organisms is intensified by cold explains the influence of a low temperature in favouring the onset of rheumatic affections. On killing the animals 48 hours after inoculation, many of them showed no other focal lesions than those of the organs in question, and in others the elective lesions were the only severe ones, the rest being insignificant.

Flexner is trying to determine experimentally whether the lesions in the elective tissues are due to the lodgment in them of a larger number of bacteria than in other organs, or whether the bacteria lodged in equal numbers in other organs are capable of surviving only in the elective one. So far the indications point to the former supposition as the correct one, and it appears that the cells of the elective tissue draw the bacteria from the circulation as by a magnet-that is, a process of absorption.

Exposure. - The view that exposure to cold and wet is an important factor in the etiology, together with the fact that the symptoms include, amongst others, pain in the region of joints, ligaments, and muscles, suggests that the morbid condition may be of a rheumatic nature. This hypothesis does not, however, materially add to our knowledge of its genesis, because it is difficult to explain exactly what is meant by the term rheumatism. If we look upon trench shin as a form of rheumatism, the great majority of cases should be classified as that variety of rheumatism which spares the joints but affects the periosteum, ligaments, nerves, and other tissues. This type is sometimes designated "abarticular rheumatism." As examples of abarticular rheumatism we may mention myalgia, rheumatic iritis, rheumatic sciatica, rheumatic polyneuritis, and rheumatic facial neuralgia. Possibly cases of so-called fibrous rheumatism of joints, a condition characterised essentially by morbid changes in the ligaments with little or no change in the interior structure of the joints, may belong to the same category.

The conception of the existence of a pathological condition which may be termed infectious fibrositis is, I think, a useful one in medicine, as it gives a clearer idea of the origin of some diseases which are now recognised as clinical entities, chiefly from the study of their symptomatology. Fibrous tissue is very widely distributed in the body, and may, indeed, be said to form the framework of the body. Moreover, its chemical composition, in common with that of bone, probably does not vary materially with the organ to which it belongs. It is therefore easy to understand that the fibrous tissue in the muscles, nerves, and ligaments will exhibit an elective affinity for the same causative agents of disease as it appears to do in the condition which is now under consideration.

\section{Diagnosis.}

In the recognition of the disease the important points are the following: (1) A history of headache and fever.in the early stage; (2) the presence of leucocytosis, even in the absence of fever; (3) pain and tenderness on pressure over the tibiæ and tibiales antici muscles ; (4) the presence of a neuritis, particularly of the upper extremity; (5) the presence of pain in the ligaments and bony prominences around joints; (6) the greater intensity of the pain in the head, muscles, bones, and joints at night; (7) the prolonged course of the disease, usually from one to three months.

The characteristics of the pain, whether the morbid process be localised in the head, bone, ligament, joint or nerve, are sometimes of value in diagnosis. As already stated, in most cases the pain is worse at night. Some patients state that its intensity is increased by damp weather, others that it is aggravated by the application of heat. A common statement is that it is of a gnawing character, with exacerbations, during which it is "jumping" or "stabbing." Headache and pain in the shins are frequently so severe at night that it is impossible to obtain sleep without the administration of morphine.

\section{Differential Diagnosis.}

The symptomatology of trench shin may closely resemble that of trench fever. Indeed, there are some writers who maintain that the two affections are the same. Major $T$. Houston and Captain J.M. McCloy are two authors who hold this view. They recognise four different types, two described by McNee and Renshaw and two by themselves. They are of the opinion that all the types have the same symptomatology at the beginning, the difference being dependent on the course and duration.

Type 1.- In this type the temperature, which may rise as high as $103^{\circ}$ or $104^{\circ} \mathrm{F}$. during the first one or two days, tends to fall on or about the third day to normal or even subnormal. It then rises again, and fever may last for six days to a week, after which the temperature falls, with complete relief of the symptoms.

Type 2.-This type is less common, and exhibits the cha. racteristics of relapsing fever. The initial attack lasts about three days, and when the temperature falls the patients feel so well that many of them have been returned to duty. Some days later the symptoms recur, often with a temperature of $103^{\circ}$ or $104^{\circ}$. This relapse differs from that seen in the first type of case, in that it is the first of a series. Hunt and McNee state that the average duration of the relapsing type is not less than three or four weeks. In individual cases it may be considerably longer than this. McNee and Renshaw state that they have seen only 20 characteristic cases of this type, but that their experimental results indicate that it may supervene on the basis of the first type, showing that both forms are simply varieties of one and the same disease.

3. Myalgic type.-In the majority of these cases there was no history of previous rheumatism. It differs from the types previously described in that there is only one period of pyrexia, lasting from a fow days to a week, whilst the myalgic pains, which are nsually limited to the lumbar region and lower limbs, especially the shins, persist after the pyrexia has disappeared, in some cases for several weeks. Pain is worse at night and in cold damp weather.

4. Septiccemic type.-In the septicæmic type the onset is almost always sudden, and fever, without intermissions, persists for as long as from 11 to 30 days. Headache is a most persistent and severe symptom, and there are sometimes definite rigors, nausea, and vomiting. These last symptoms appear to be comparatively rare in the other three forms. After the temperature has fallen to normal recovery is usually rapid, there being no recurrence of the pains.

According to the above classification the affection which forms the subject of this paper would be of the myalgic type. I am not convinced that the classification of Major Houston and Captain McCloy is correct. The important symptoms of trench shin, in addition to the fever and leucocytosis, are headache and other symptoms which might be called rheumatic. The parts involved have been referred to in discussing the symptomatology. In trench fever headache and pain in various parts may be present, but in the great majority of cases these symptoms are not outstanding and are only present during the febrile stage. In some cases, however, pain in the shins may be present for two or three weeks, but this pain is not usually intense. Moreover, headache and soreness or pain in the back and other parts are common manifestations in the febrile stage of many morbid conditions. The difference between the origin of these symptoms and the origin of the manifestations of trench shin is dependent upon the difference in the affinities of the bacteria for fibrous tissue.

\section{Prognosis and Treatment.}

The course of the disease is very slow, but, as will be seen later, it varies considerably in individual cases. Recovery eventually takes place, however, after a period of two or three weeks to two or three months. As far as we know, there are no sequelæ. The best guide to progress in recovery is the intensity of pain, and if it gradually diminishes from day to day recovery may be expected in from two to three weeks. The leucocyte count also sometimes gives valuable indications in regard to prognosis, as recovery within a short time may be looked for if it is within normal limits.

The treatment is chiefly preventive. It is obvious that one of the first essentials is the avoidance of anything, such as tight boots or puttees, which is likely to obstruct circulation. Lorrain Smith, Ritchie and Dawson suggest the advisability of substituting moleskin leggings for puttees. These provide the protection of an ample cushion of air and drain more readily than puttees, thus minimising the loss of heat. Delépine suggests waterproof bags made of oiled silk, similar in shape to fishing-boots. The outer sock, which should be sufficiently large to draw over the oilskin, should be made of material which is not liable to shrink when wet.

In a book describing the preventive measures which were found most effective in the winter campaign of the Japanese Army in Manchuria it is recommended that the feet, legs, 
and, if necessary, the whole of the body, should be thoroughly rubbed with animal fat or animal oil. In order to obtain the maximum effect the oil should be of high boiling-point and used in considerable quantity. Daily massage of the parts between periods of trench duty has also been recommended. A similar preventive measure has been much used in the present war-that is, applying vaseline or whale-oil liberally to the feet and legs.

In the curative treatment measures for treatment of an infectious disease are indicated. Rest in bed is essential. Acetyl-salicylic acid and phenacetin may be tried for the relief of pain, but it is often necessary to give morphia. In cases in which the pain in the tibiæ has been very severe an incision through the periosteum has sometimes been made, and is said to be of much value.

McNee and Renshaw, on the assumption that antibodies to the infected virus might develop in the course of spontaneous cure, removed 20 c.c. of blood from a patient 10 or 12 days after his last relapse, and four hours later injected the serum into the veins of two who were just beginning to relapse. It appeared to have no influence whatever on the course of the disease.

\section{Illustrative Cases.}

CAse 1.-Private $\mathbf{H}$. The patient had been formerly a coal-miner, and had been in the service for one and a half years. His habits had been temperate and his previous health very good. He was admitted
to No. 4 Canadian General Hospital, Salonica, on Jan. 27th, 1916. He stated that his illness commenced three days before admission, the first symptoms being headache and pain in the shins. He attributed the pain in the shins to exposure and a march of 19 miles. On the march he wore puttees, but they were not tight.

Present condition.-The patient complains of pain and a burning sensation in the shins, the dorsal surface of the feet, and the central portions of the tibiales antici, the pain being more severe at night and in wet weather. At night it is continuuus, with exacerbations every few seconds, during which it is stabbing in character. There is pain on extension of the foot. The parts previously referred to are painful on extension of the foot. The parts previously referred to are painful on deep pressure. Reflexes normal and active. No disturbance

CaSe 2.-Sergeant-Bugler M. The patient, aged 28, had suffered from rheumatic fever at the age of 10 years. He had been in South Africa for two years and in India for seven years, and during these nine years had had three attacks of fever. He stated that aching pains in the leg had been fairly constant during the last month. His general health had been fairly good, but he felt weak and his appetite good condition. There was no gastro-intestinal disturbance. During the last three weeks he had been in the hospital, but the pain had not been relleved.

Present condition.-Oa examination the heart, lungs, and urine were found to be normal. White blood corpuscles 22,000. Temperature normal. Soreness and pain are limited to the inner surfaces of the tibia and the dorsal surtaces of the feet. The tibiales antici are not
involved. Both flexion and extension are more painful than normal. Reflexes normal.

CASE 3.-Sergeant B., admitted to No. 4 Canadian General Hospital on Jan. 25th, 1916 . He stated that about the middle of last December he began to suffer from headache and pain in the back and thinhs, especially on rising in the morning. It usually subsided after he had leave the bick and thighs and become localised in the shins and front and side of the knees. There was also slight pain in the elbows.

Present condition. - Pain in shins and at the side of the knees over the tuberosities of the femur. It was of a dull throbbing character the tuberosities of the femur. It was of a dull thro

CASE 4.-Sergeant W., aged 31, admitted to No. 4 Canadian General Hospital, Salonica, on Jan. 24th, 1916. The illness commenced on Jan. 16th with fever, headache, and pain over the shins, which continued for four days, being worse at night. The headache lasted three days. When taken ill the patient was working at headquarters
and had had no marching or exposure sieco December, when he was in and ha

Present condition.-There is marked tenderness over the bellies of the tibiales antici on both sides, and slight tenderness over the crests of the tibiæ, together with occasional pain in the knees. Dorsiflexion White blood corpuscles 16,000 . Examination otherwise negative.

CASE 5.-Private $\mathbf{W}$., aged 26. Two months previously, while in Egypt, he had found that he was unable to march owing to pain and stiffness in the legs. There was no fever. He had not been in the
trenches or exposed to cold. During his previous seven months in France he had had no trouble.

Fresent condition.-On admission to No. 4 Canadian General Hospital on Jan. 26th complained of pain in the knees and shins. There was marized tenderness over the tibiales antici on both sides,
especially above the ankles along the course of the tendon, and slight especially above the ankles along the course of the tendon, and slight was worse at night, and not relieved by heat. Dorsiflexion of the foot painful. No fever. White blood corpuscles 14,000. Examination otherwise negative. On Feb. 5th the white blood corpuscles numbered
13,500 . Pain still severe, the slight tenderness ozer the tibize remaining as before.

Case 6. - Private L., aged 34, admitted to No, 4 Canadian Generai began to on Jan. 24th, 19,6. Tez days previously, whilst on guard, he came on quite suddenly. He had been trench digging both in France and Salonica, but bad not recently been exposed much to either cold

Present condition.-There is tenderness over the internal surfaces and the crests of the tibic. The tibiales antici are tender on pressure.
Pain is worse at night and increased by heat, There is a callous area 12,000 . On Feb. st marked pain and tenderness 2,000. On Feb. 1st marked pain and tenderness over internal surface of the tibiz, in bellies of tibiales antici on both sides; worse at night. Since admission the temperature has been irregular, going up to
White blood corpuscles 10,000 . Examination otherwise negative.

CASE 7.- Lance-Sergeant B., aged 24, had enlisted in Toronto on May 28th, 1015. In England Dec. 1st, 19i5. In France Feb. 20th, 1916. Had an attack of $l a$ grippe about the end of February, 1916 The present illness began during the first week of June with headache, pains in the joints and muscles, and fever. The headache was aggravated by coughing and was worse at night. The patient was sent to a held hospital, where he remained for nine or ten days. Whilst there the temperature was normal or subnormal in the morning and slightly Hevated at night. He returned to duty, but was unable to carry on.
He was sent to hospital. Boulogne, and from thence, on June 30 th, to the Ontario Military Hospital, Orpington.

Present, condition.-Complained of weakness, of loss of appetite, and of pains in shoulders, elbows, wrists, knees, and ankles. Three days ater-i.e., July 3rd-pain experienced in shins, which gradually became worse, and at the same time the pain in the joints became
less severe. In about a fortnight the pain in the joints subsided. That in the shin bones was worse at night and seemed aggravated by dampness. Relief for an hour or two was sometimes obtained by taking 10 grains of acetyl-salicylic aeid. The pain was of a gnawing taking 10 grains of acetyl-salicylic acid. The pain was of a gnawing
character and was localised in the middle third of the tibir. The character and was localised in the middle third of the tibix. The
surfaces of the bones were sensitive and tender on pressure. Since surfaces of the bones were sensitive and tender on pressure. Since
admission the temperature had been normal or subnormal. On admission the temperature had been normal or subnormal. On
August 13th white blood corpuscles, 15,400 ; polymorphonuclears, 65 per cent.; lymphocytes, large and small, 31 per cent.; eosinophiles, 4 per cent. On the 25 th the patient complained of a dull pain and tenderness on pressure at the back of the right shoulder, at about the level of the sixth or seventh cervical vertebra. On the 28th there was still pain at the back of the right shoulder. There was also $p$ tin along the posterior part of the internal surfaces of the arm, extending adjacent balf of the ring finger. The ulnar nerve was sengitive to pressure at the elbow. No material weakness of muscles supplied by ulnar nerve. Electrical reactions normal. Hyperæsthesia of little finger and adjacent balf of ring finger. Pain at back of right shoulder. produced by raising the right arm from the side. Slight pain in shin bones. On sept. 9th the pain had almost gone from the
shins, and that in the right arm had lessened. On Oct. 3rd the patient was free from pain and his general condition was fair.

The interesting points of this case are : (1) During the first two or three weeks of the illness the pain was chiefly limited to the joints ; (2) the tibiæ became involved during the third week; (3) the ulnar nerve became involved during the eighth or ninth week; (4) the comparatively high leucocyte count in the absence of fever.

CASE 8.-Sergeant B., aged 43. Service 23 months. Health before enlistment good. On July 7th had been operated upon for piles at Dannes Camiers, and subsequently made a good recovery. About three or four weeks later the present illness began with pain at the back of the neck and left shoulder, the temperature being elevated. Three days later pain in shins and forearms.

Present condition.-August 13th : Complaint: Pain in shins, fore arms, and in a small area near the seventh cervical vertebra at the back of the left shoulder. Much worse at night. Pain in shins continues and of a gnawing character, with exacerbations, during which it radiates to the thighs and feet and is equally severe in botb legs. The posterior and internal surfaces and crests are slightly sensitive. Pain and tenderness in the tibia are limited to the middle thirds of the bones. In the forearms there is little pain, but there is tenderness on pressure for about 5 inches above the wrist in a longitudinal line between the radius and ulna and at the back of the left shoulder just
to the left of the seventh cervical vertebra. Raising the left arm from to the left of the seventh cervical vertebra. Raising the left arm from the side causes pain in the back of the left shoulder-joint. Temperature
slightly elevated. White blood corpuscles, 15,500. The differential slightly elevated. White blood corpuscles, 15,500. The differential count gave the following percentages: polymorphonuclears, 75 ; smal mononuclears, 15: large mononuclears, 6.5 ; basophiles, 1.5 ; eosino
philes. 1.5 ; transitional. 0.5 . Sept. 2nd: Very little pain in shins. Area at back of shoulder and forearm still tender. Temperature has been normal $f$, $r$ six days. 5th: Improved ; very little pain, and only
slight tenderness in areas mentioned above. Oct. 18th: Pain slight tenderness
completely gone.

In this case, although the pain at the back of the left shoulder was similar to that of Case 7 , there was no pain along the course of the ulnar nerve.

CASE 9.-R. H. L., aged 33, had enlisted in February, 1915, and was sent to France in February, 1916. The present illness commenced on Sept. 2nd, 1916, with headache, pain in arms, legs, aıd back, all these symptoms being worse at night. slight fever during the first three symptoms being worse at night. Slight fever during the first three
days. The patient was seat to a clearing station, and thence to a days. The patient was seat to a clearing station, and thence to a
hospital in Boulogne, and ten days later to the Ontario Miititary hospital in Boulogne
Hospital, Orpington.

Present condition--Complaint : Pain in shins, back, thighs, biceps, and in tibiales antici. Worse at vight, and all the painful areas
tender on pressure. On coughing pain felt at the back of the head. tender on pressure. On cou
White blood corpuscles 11,000 .

CASE 10.-K. J. K., aged 49. Service nine months. Enlisted February, 1916, and was sent to France the following month. Health good until Augus 25th, when he began to suffer from pain in the left sensation of "ays later pain was felt behind the left shoulder and a fingers of the left hand. He paraded sick, and was sent down the line to Boulogne, and thence two days later to Ontario Military Hospital, Orpington.

Present condition.-Sept. 3rd : Complaint: Pain and sensation of "pins and needles" in little and ring fingers of left hand, in ulnar side neck forearm, in the back of the left shoulder and left side of the neck, and slight pain in the left knee-joint. All the painful areas muscles supplied by the ulnar nerve react to the faradic current.
10th: No pain in left knee. Condition of left arm remains about the 
same. White blood corpuscles 10,400 . Oct. 1st : Less pain in left arm. Nov. 1st: Strength of left hand improved. Coughing causes severe pain in left side of chest. Nov. 21st: Slight pain in ulnar side of arm Pain on left side of chest on coughing. Dec. 1st: Patient stil complains of slight pain in hand, left shoulder, and along ulnar side of left arm.

In this case the special localisations of the morbid process were probably limited to nerve and ligament.

CaSe 11.-Private L. Patient enlisted in September, 1914, and was sent to France in August, 1916. In November, 1916, he reported ill on account of loss of power in right forearm and fingers. He suffered no pain exeept headache at the beginning of his illness. Immediately prior to becoming ill he had been exposed in the trenches to cold and wet, and one week after the beginning of his illness pain began in the hins. This lasted about ten' days. Admitted to Ontario Military Hospital Dec. 3rd, 1916.

Present condition.-Patient unable to extend the right wrist (wristarop) Flexion and extengion of right elbow-joint present, but on fored flexion at this joint the eupinator longus does not contract. corced fiexion at this joint the eupinator longus does not contract. Inabilty to extend the proximer the back of the thum antial anesthesia. Wxtensor muscles of hand and suplnator longus react to faradic current, but th m.C.C. A.C.C. greater than K.C.C. Heart, lungs, and abdominal organs normal. White bloon corpuscles, 10,600; polymorphonuclears, 53 per cent.; 1 mmphocytes, 47 per cent. Jan. 24th : Patient very much improved. Can extend the hand slightly. Feb. 8th: Recovery.

This case was sent as one of musculo-spiral paralysis of unknown origin. From the clinical history I should judge that it may be classed with trench shin.

$$
\text { Bibliography. }
$$

1. Herringham, Sir W.: Quarterly Jour. Med., Oxford, 1915-16, x., 429.

2. Hunt and Rankin: Cited by Sir W. Herringham, loc. cit.

Hunt and McNee: Quarterly Journ. Med Oxford, 1915-16, 442

4. McNee and Renshaw : Brit. Med. Jour. 1916, i. 225

5. Houston and McCloy: THE LANCET, 1916, ii., 632 .

6. Lorrain Smith, Ritchie, and Dawson: Journ. Pathol., 1915-16, $\mathrm{xx} ., 160$.

7. Campbell, H. : Brit. Med. Jour., 1917, ii., 578.

. Llewellyn Jones : "Fibrositis," 1916.

9. Rosenow : Journ. Amer. Med. Assoc., 1915, 1xiv., 1968; 1xv., 1687.

Journ. Infec. Dis., March, 1915.

10. Flexuer: Journ. Experimental Med., 1., 211.

11. Delépine: Brit. Med. Jour., 1915, ii., 888; The Lancer, 1915, i., 271,463

\section{AMEBIC DYSENTERY AND ITS RELATION- SHIP TO A FORM OF DIARRHCEA OCCURRING IN EGYPT.}

By G. MARSHALL FINDLAY, M.B., Oh.B. EDIN., TEMPORARY SURGEON, ROYAT NAYY.

DURING the past year the opportunity has been given me of studying the illnesses among naval ratings during the first few months of their residence in Fyypt. Diarrhœe and amcebic dysentery have been by far the commonest causes of ill-health, and I am here suggesting a relationship between these two conditions.

Diarrhoea with Gastric Symptoms.

Of the Europeans who arrive in Egypt for the first time, it is probable that nearly 90 per cent. suffer from a form of diarrhoea, associated with gastric symptoms, which is so common that it is known among Anglo-Egyptians as "Egyptian stomach." The first attack usually comes on within a fortnight of arrival in the country, while subsequent attacks may recur at intervals of from one to two weeks. After a residence of roughly six months the disease entirely subsides and does not again appear. Owing to the comparatively slight symptoms the condition has failed to attract any very great notice among specialists in tropical medicine.

A typical attack usually begins in the early hours of the morning, although it may commence at any hour of the day or night. At first there is only slight abdominal uneasiness, but this is quickly followed by definite griping pains, confined for the most part to the epigastric and umbilical regions. There is a marked desire to empty the bowels, though evacuation gives little relief. As many as 10 or 15 stools may be passed during the day. Nausea and vomiting are present in about three-quarters of the cases, while in a few instances headache is a marked symptom. The temperature is slightly raised in the evening $-98.8^{\circ}$ to $99.8^{\circ} \mathrm{F}$., while the posterior part of the tongue is covered with a brownish fur. The diarrhoa does not persist for more than two or three days at the outside; it is usually followed by constipation. About a week generally elapses before the bowels regain their normal action. A similar attack may recur within a fortnight or three weeks of the original attack. The fæces are always fluid in character and in a typical case resemble pea-soup; blood and mucus are absent. The blood shows no definite changes, except a slight but constant increase in the large mononuclear leucocytes (10-18 per cent.).

The condition is not confined to any particular class; officers and men, whether living ashore or afloat, are equally affected. It has no relationship to the presence of sandstorms, which in this country are oonfined to the early spring months. Dietetic errors are hardly likely to be responsible for so prevalent a condition. There appears, however, some ground for considering the disease to be of an infective character. Thus, of $\mathbf{1 2 0}$ sailors arriving in Egypt in March, 1916, 30 had reported sick with the condition by the end of July, while a further 50, on questioning, confessed to having had attacks of diarrhoea and gastritis, though they had not deemed the occurrence worth reporting. Since August these men have been entirely free from this condition, though they have not been exempt from attacks of amœbic dysentery. As a general rule, the diarrhœea and gastritis are more severe in persons under 20 and over 40 years of age.

\section{Amobic Dysentery.}

The second most important cause of sickness among naval ratings has been amobic dysentery. Cases of this condition can be separated into two classes: (1) Old dysenterics who have relapsed; (2) first attacks in persons who have never before been abroad. In the present series of cases the former class constitute nearly 20 per cent. of the total number, and as in the majority of instances the dysentery was first contracted in Gallipoli, during the Dardanelles campaign, since then these cases must have been acting as "convalescent carriers." Doubtless an examination of the stools of everyone in Egypt, if such a thing were possible, would reveal the presence of a very large number of carriers of this description.

For the most part, the cases all conformed to the classical type of a mild amcebic dysentery, with blood and mucus in the stools. The clinical symptoms were headache, lassitude, slight abdominal pain, and diarrhœe, with some tenesmus. The temperature was slightly elevated, but rarely exceeded $100^{\circ}$. On microscopical examination Entameeba histolytica was found to be present in the stools in every instance, though, as is so common in this form of dysentery, the excretion of entamœbæ was of an intermittent character.

Apart, therefore, from the condition of the stools, the clinical symptoms were very similar to those described as occurring in the condition known as " Egyptian stomach." In the case of first attacks of dysentery, the dysenteric symptoms do not as a rule manifest themselves until the patient has been resident in the country for a few weeks at least. In one instance, however, a sailor, 18 years of age, developed a typical attack of amœbic dysentery two days after arrival in Egypt. The patient stated that he had never before been abroad, but two years previously had had an attack of dysenteric-like symptoms. Inquiry, however, showed that both the boy's father and brother were in the Army ; the former had returned from India shortly before the patient's first attack. This, therefore, appears to have been an autochthonous case occurring in England. An attack of dysentery may, however, manifest itself after a residence of some months or even years, but in many cases there appears to have been a previous history of "Egyptian stomach." Thus inquiry into 40 cases of dysentery occurring for the first time elicited that in 36 instances there was a previous history of one or more attacks of "Egyptian stomach," preceding the onset of dysenteric symptoms. The intervals elapsing between the last attack of "Egyptian stomach" and the commencement of the dysentery varied from a few days to some months.

\section{Relationship of the Two Affections}

In order to determine whether there was any relationship between the two conditions a microscopical examination of the fæces was carried out in 110 cases of "Egyptian stomach." In regard to the presence of entamobæ, the following results were obtained :-

Entamœbæ entirely absent

Entamceba coli present ...

Entamoba histolytica

8 cases.

Encama minuta (Elmassian) ... $\ldots \ldots$

ntamceba minuta (Elmassian), together $\begin{array}{llllll}\text { with tetragena cysts ... } & \ldots & \ldots & \ldots & \ldots\end{array}$ 